\title{
EFECTO DEL USO DE MEDIO SECUENCIAL HUMANO EN LA PRODUCCIÓN DE BLASTOCISTOS DE HEMBRA OVIS CANADENSIS MEXICANA POR CLONACIÓN MANUAL INTERESPECIES
}

\author{
EFFECT OF SEQUENTIAL HUMAN MEDIUM USE IN THE PRODUCTION \\ OF BLASTOCYSTS OF FEMALE OVIS CANADENSIS MEXICANA \\ BY INTERSPECIES HANDMADE CLONING
}

\author{
JosÉ Roberto VAZQUEZ-AVENDAÑO, ${ }^{1}$ SARAHÍ HERNÁNDEZ-MARTÍNEZ, ${ }^{1}$ JosÉ ERNESTO \\ HERNÁNDEZ-PICHARDO, ${ }^{2}$ JUAN ARTURo RIVERA-REBOLLEDO, ${ }^{3}$ DEMETRIO Alonso \\ AMBRIZ-GARCÍA ${ }^{1}$ Y MARÍA DEL CARMEN NAVARRO-MALDONADO ${ }^{1, *}$
}

\begin{abstract}
${ }^{1}$ Departamento de Biología de la Reproducción, División de Ciencias Biológicas y de la Salud, Universidad Autónoma Metropolitana Unidad Iztapalapa. Av. San Rafael Atlixco, Núm. 186, Col. Vicentina, Delegación Iztapalapa, Ciudad de México, México C.P. $09340<$ robertmizer@gmail.com>; <neverblackland@hotmail.com>; <deme@xanum.uam.mx>.

${ }^{2}$ Departamento de Producción Agrícola y Animal, División de Ciencias Biológicas y de la Salud, Universidad Autónoma Metropolitana, Unidad Xochimilco. Calzada del Hueso Núm.1100, Col. Villa Quietud, Delegación Coyoacán, Ciudad de México, México, C.P. 04960 <mvzjehp@yahoo.com>.

${ }^{3}$ Dirección General de Zoológicos y Vida Silvestre, Secretaría del Medio Ambiente de la Ciudad de México. Av. Chivatito S/N, $1^{\text {a }}$ Sección del Bosque de Chapultepec, Colonia San Miguel Chapultepec, Delegación Miguel Hidalgo. C.P. 11580 Ciudad de México, México <jarturorivera@yahoo.com.mx>.

* Autor de correspondencia: <carmennavarro2006@yahoo.com.mx>.

Recibido: 30/09/2016; aceptado: 09/05/2017

Editor responsable: Vinicio Sosa.
\end{abstract}

Vazquez-Avendaño, J. R., Hernández-Martínez, S., HernándezPichardo, J. E., Rivera-Rebolledo, J. A., Ambriz-García, D. A. y Navarro-Maldonado, M. C. (2017). Efecto del uso de medio secuencial humano en la producción de blastocistos de hembra Ovis canadensis mexicana por clonación manual interespecies. Acta Zoológica Mexicana (n.s.), 33(2), 328-338.

RESUMEN. Efecto del uso de medio secuencial humano en la producción de blastocistos de hembra Ovis canadensis mexicana por clonación manual interespecies. Desde el evidente problema del peligro de extinción que enfrenta un número significativo de especies silvestres a nivel mundial, se han aplicado biotecnologías encaminadas a promover su conservación y reproducción. Tal es el caso de la transferencia nuclear de células somáticas (TNCS) interespecies que ha sido aplicada y ha producido exitosamente embriones y crías nacidas vivas en algunas de estas especies. Sin embargo, la TNCS interespecies aún debe lidiar con otros problemas como la baja tasa de producción de embriones y de supervivencia de las crías nacidas (3-6\%). Problemas que, entre otros, involucran la alta incidencia de fragmentación embrionaria. Los estudios son ahora dirigidos a resolver estos obstáculos, determinando el efecto de diferentes medios o suplementos utilizados en la producción in vitro de embriones. El objetivo de este estudio fue aplicar una variante de la TNCS interespecies (Clonación ManualHMC) para la producción de embriones, determinando el efecto del uso de medios secuenciales humanos, en el borrego salvaje mexicano
Vazquez-Avendaño, J. R., Hernández-Martínez, S., HernándezPichardo, J. E., Rivera-Rebolledo, J. A., Ambriz-García, D. A., \& Navarro-Maldonado, M. C. (2017). Effect of sequential human medium use in the production of blastocysts of female Ovis canadensis mexicana by interspecies handmade cloning. Acta Zoológica Mexicana (n.s.), 33(2), 328-338.

ABSTRACT. Effect of sequential human medium use in the production of blastocysts of female Ovis canadensis mexicana by interspecies handmade cloning. Faced to the notable problem that a significant number of world wild species are endangered, some biotechnologies such as the interspecific somatic cell nuclear transfer (SCNT), have been applied to raise their reproduction and conservation. This technology has been successfully applied by producing embryos and live offspring in some of these species. However, the interspecific SCNT still has to solve problems such as the low embryo production and offspring survival rates (3-6\%). These problems, among others, involve a high incidence of embryo fragmentation and in order to solve them, most studies are now aimed to determine the effect of different culture media or supplements used for in vitro embryo production. Therefore, the aim of the present study was to use a variant of the interspecific SCNT technique (Handmade cloning-HMC) for embryo production, determining the effect of human sequential media in the endangered Mexican wild sheep O. c. mexicana. Results indicate that the embryo production increased when using human sequential media, allowing 
amenazado de extinción $O$. c. mexicana. Los resultados muestran que la producción de embriones incrementa con el uso de medios secuenciales humanos, permitiendo al embrión desarrollarse hasta la etapa de blastocisto ( $16 \%$ vs. $0 \%, \mathrm{P}<0.05)$. Este es el primer reporte de clonación exitosa de embriones de hembra O. c. mexicana en México.

Palabras clave: Ovis canadensis mexicana, clonación manual, medio secuencial humano.

\section{INTRODUCCIÓN}

México se localiza en el tercer lugar a nivel del continente Americano en megabiodiversidad, albergando el mayor número de mamíferos y es posible que en un contexto mundial tenga uno de los inventarios más altos de estas especies. Aunque el país está representado por un número considerable de órdenes, los mamíferos son un grupo singular, al considerar su riqueza de especies, el número de endemismos y sus relaciones biogeográficas (Escalante et al., 2002). Sin embargo, existe un gran número de mamíferos silvestres que se encuentran amenazados o en riesgo de extinción. Tal es el caso del borrego cimarrón (O. c. mexicana) (Shaw 1804), una especie emblemática de nuestro país sujeta a protección especial en la Norma Oficial Mexicana 059 (NOM-059-SEMARNAT-2010), ya que durante los últimos años se ha observado una reducción considerable de sus poblaciones como consecuencia de diferentes actividades antropogénicas, como la fragmentación del hábitat y la caza ilegal. Debido a su actual estatus de vulnerabilidad, es necesario implementar estrategias reproductivas que puedan disminuir su riesgo de extinción, los estudios generados hasta el momento en el borrego cimarrón solo se limitan al monitoreo de poblaciones, descripciones anatómicas y seguimiento del ciclo estral. Sin embargo, las biotecnologías reproductivas no han figurado dentro de estos estudios, por lo cual su implementación podría ofrecer una alternativa de conservación de la especie (Navarro et al., 2015).

La Transferencia Nuclear de Células Somáticas (TNCS), es una biotecnología reproductiva mediante la cual se obtienen embriones genéticamente similares al donador de la célula somática, para llevarla a cabo es necesario la unión de dos tipos celulares: la célula somática donadora de núcleo (carioplasto) que es fusionada con un ovocito enucleado (citoplasto) que será el receptor de la información genética de la célula somática, estás células pueden pertenecer a una sola especie o ser interespecies. Actualmente se han descrito varios métodos para llevar a cabo la transferencia de núcleos. La innovación de la TNCS mediante la clonación manual (Vajta 2001) the embryos to reach the blastocyst stage ( $16 \%$ vs. $0 \%, \mathrm{P}<0.05)$. This is the first study that reports the successful cloning of female $O$. $c$. Mexicana embryos in Mexico.

Key words: Ovis candensis mexicana, handmade cloning, sequential media.

(HMC, por sus siglas en inglés Handmade cloning), se ha desarrollado como una nueva técnica que ha permitido prescindir del uso de equipos especializados (Bosch, 2005).

La HMC difiere de los métodos tradicionales de TNCS en que para obtener el citoplasto, el ovocito es enucleado manualmente usando micronavajas para eliminar el primer cuerpo polar y la placa metafásica. Dos citoplastos se fusionan con un carioplasto mediante un estímulo eléctrico, formando un triplete celular que dará lugar a una nueva célula que será activada químicamente para su división, desarrollando un embrión clon del individuo del que fue obtenido el carioplasto. Éste puede implantarse en una hembra receptora para que continúe el desarrollo del embrión hasta obtener crías nacidas (Vajta, 2003).

La clonación manual ha permitido producir embriones de mamíferos domésticos, tales como: bovinos (Vajta et al., 2003), porcinos (Du et al., 2008), caprinos (Akshey et al., 2008), ovinos (Zhang et al., 2013), entre otros. En cuanto a especies silvestres, existen dos estudios de producción de embriones por clonación manual interespecies, el antílope tibetano (Pantholops hodgsonii) (Yu et al., 2011) y el búfalo Arnee (Bubalus arnee) (Priya et al., 2014).

Sin embargo, el éxito de la transferencia nuclear en la obtención de blastocistos es bajo, ya que la mayoría de los embriones quedan arrestados en la etapa de mórula o sufren alteración durante la división celular (fragmentación), debido a factores como la calidad del ovocito, el tipo de célula somática donadora de núcleo, el número de pasajes celulares, el método de clonación empleado, la sincronización entre el carioplasto y el citoplasto, el medio de cultivo (simple o secuencial), el sistema de cultivo para la producción de embriones in vitro, etcétera (Solter, 2000; Tian et al., 2003; Fujimoto et al., 2011).

En la producción de embriones humanos, en el caso de los medios simples utilizados, el embrión permanece en dicho medio durante todo el tiempo de cultivo in vitro con un recambio al día tres de cultivo, mientras que, en los medios secuenciales, el embrión es cultivado en un medio de desarrollo hasta la etapa de mórula que corresponde 
con el día tres de cultivo. Posteriormente es cambiado a otro medio para que alcance la etapa de blastocisto hasta el día cinco de cultivo (Sfontouris et al., 2017).

Existen controversias en cuanto a los resultados, ya que algunos autores al utilizar medios simples como es el KSOMaa (Por sus siglas en inglés Potassium Simplex Optimized Medium with aminoacids), mejoran la tasa de blastocistos producidos por ICSI (por sus siglas en inglés Intracytoplasmic Sperm Injection) (Sfontouris et al., 2017), otros estudios en humanos sugieren que el uso de un solo tipo de medio de cultivo en embriones en estado de preimplantación disminuye la eficiencia global de la producción de embriones y que, utilizar medios de cultivo secuenciales permite mejorar el desarrollo en blastocitos, la viabilidad, implantación y gestación del embrión (Findikli et al., 2004).

En rumiantes, se reporta el uso de SOFm (por sus siglas en inglés Synthetic Oviductal Fluid modified) como medio único para el desarrollo de embriones producidos por fertilización in vitro (FIV) en ovinos (Robledo-Verduzco et al., 2009) y caprinos (Soberano et al., 2011), o producidos por clonación manual en ovinos (NavarroMaldonado et al., 2016). Sin embargo, en ninguno de estos estudios los embriones producidos alcanzaron la etapa de blastocisto.

Otros autores han comparado el uso de medios secuenciales SOF1 y SOF2 vs. medios secuenciales G1.2/G2.2 en la clonación de embriones de caprino, con tasas de desarrollo en blastocistos de 21 y 30-35\%, respectivamente (Hosseini et al., 2015). Mientras que García-García et al., (2007) utilizaron medios secuenciales G1.3/G2.3 en FIV en ovinos obteniendo $24 \%$ de blastocistos vs. $21 \%$ en SOF.

También se han utilizado medios secuenciales KSOMaa 1 y 2 (Por sus siglas en inglés Potassium Simplex Optimized Medium with aminoacids 1 y 2) en la clonación de embriones de ovino (Aghaz et al., 2016). Estos estudios permitieron el desarrollo embrionario a la etapa de blastocisto en un 42\%. Mientras que Arias et al., (2013), combinando medios secuenciales SOF y KSOM, y variando el tipo de fuente de proteína con la cual suplementarlos, encontraron que la combinación de KSOM con $0.4 \%$ BSA (por sus siglas en inglés Bovine Serum Albumin) y KSOM con 5\% de SFB (Suero Fetal Bovino) permitieron las mejores tasas de desarrollo a blastocistos en embriones de bovino (28\%).

Se ha comparado el uso de RVCL (Por sus siglas en inglés Research Vitro Cleave Medium) vs. G1/G2 en clonación manual interespecies (caprino-ovino), encontran- do mejores tasas de producción de mórulas y blastocistos (65\% vs. 42\%, respectivamente) (Khan et al., 2014).

Existe un trabajo de FIV en bovinos que reporta el uso de medios secuenciales humanos para el desarrollo embrionario, pero sus resultados no mostraron diferencias significativas entre el SOF y estos medios ( $24 \%$ vs. $23 \%$, respectivamente) (Cevik et al., 2014).

A la fecha, no existen reportes de producción in vitro de embriones de ovino silvestre por clonación manual utilizando medios secuenciales humanos (Cleavage y Blastocyst). Por lo que el presente estudio se llevó a cabo con la finalidad de producir embriones de hembra cimarrona Ovis canadensis mexicana mediante clonación manual interespecies, utilizando medios secuenciales humanos, como una alternativa para la producción de embriones y la conservación de esta especie endémica en riesgo.

\section{MATERIALES Y MÉTODOS}

Todos los reactivos utilizados en este trabajo fueron suministrados por Sigma Aldrich ${ }^{\circledR}$ (St. Louis, MO, USA) a menos que se indique lo contrario. Todas las incubaciones se realizaron a $38{ }^{\circ} \mathrm{C}$ y $5 \%$ de $\mathrm{CO}_{2}$ en aire y humedad a saturación.

Obtención de Carioplastos. De acuerdo al protocolo de Navarro et al., (2016) con algunas modificaciones, se obtuvo una muestra de $0.5 \mathrm{~cm}^{2}$ de piel de oreja de una hembra de O. c. mexicana perteneciente a la Dirección General de Zoológicos y Vida Silvestre (DGZVS) de la Secretaría del Medio Ambiente, de la Ciudad de México. El muestreo se llevó a cabo por el personal capacitado de la DGZVS durante el manejo de rutina efectuado a los animales y la obtención del tejido fue debidamente autorizada por la Secretaría de Medio Ambiente y Recursos Naturales (SEMARNAT), permiso de colecta científica SGPA/DGVS/07250/15.

El tejido de piel se transportó al laboratorio en un tubo Eppendorf de $1.5 \mathrm{~mL}$ conteniendo $1 \mathrm{~mL}$ de DPBS (por sus siglas en inglés Dulbecco's Phosphated Buffered Saline, In Vitro S.A. de C.V.) suplementado (2\% de AntibacAntifun 100X, Microlab; conteniendo 10,000 unidades de Penicilina, $10 \mathrm{mg}$ de Sulfato de Estreptomicina y $25 \mu \mathrm{g}$ de Anfotericina B por mL). En el laboratorio, se retiró el excedente de pelo al tejido, se desinfectó con alcohol al 70\% y se lavó con DPBS suplementado. Posteriormente el tejido fue sometido a disgregación mecánica y enzimática utilizando colagenasa tipo I y tipo II (2 mg/mL. Gibco) y se colocó en un oscilador dentro de una estufa precalen- 
tada a $37^{\circ} \mathrm{C}$ durante 3 horas. La acción de la colagenasa se detuvo adicionando $5 \mathrm{~mL}$ de DMEM-suplementado (Por sus siglas en inglés Dulbecco Minnimal Essential Medium) (88\% DMEM, In Vitro, S.A. de C.V.; 10\% de Suero Fetal Bovino-SFB, Microlab; 2\% Antibac-Antifun, ajustando $\mathrm{pH}$ a 7.4 con Bicarbonato de Sodio). La solución se centrifugó a 500 x g por 10 minutos descartando el sobrenadante. El botón celular se sembró en una caja Petri y se cultivó durante 7 días hasta la confluencia celular, para posteriormente efectuar un pasaje celular. Para ello, las células se sometieron a una reacción enzimática añadiéndoles $700 \mu \mathrm{L}$ de Tripsina-Verseno (0.05\%-0.05\%, In Vitro, S.A. de C.V.) para desprenderlas de la base de la caja de cultivo. Posteriormente se agregaron $2 \mathrm{~mL}$ de DMEM suplementado y se centrifugaron a $150 \mathrm{x}$ g durante 6 minutos. Se descartó el sobrenadante y el botón celular se homogenizó nuevamente en $0.5 \mathrm{~mL}$ de DMEM suplementado, la mitad de la población celular se criopreservó en Dimetilsulfóxido (DMSO, In Vitro, S.A. de C.V.) y la otra se resembró en una caja de Petri para proseguir los cultivos (Navarro et al. 2016). En la clonación se utilizaron fibroblastos del $1^{\circ}$ al $14^{\circ}$ pasaje celular.

Maduración in vitro de ovocitos. Se obtuvieron ovarios de ovejas domésticas adultas (Ovis aries) sacrificadas en un rastro en Nezahualcóyotl, Estado de México, México, los cuales se transportaron en solución salina al 0.9\% a una temperatura de $25-30{ }^{\circ} \mathrm{C}$ en un lapso no mayor a una hora.

Siguiendo el método descrito por Navarro-Maldonado et al., (2016) con algunas modificaciones, los complejos ovocito-cúmulo (COC) se obtuvieron por aspiración de folículos ováricos (2 a $8 \mathrm{~mm}$ ) con una aguja hipodérmica calibre 18; el medio de aspiración empleado fue TCM199 con Hepes (Tissue Culture Medium-Hepes, por sus siglas en inglés, In Vitro, S.A. de C.V.), suplementado con $100 \mathrm{UI} / \mathrm{mL}$ de heparina. Se seleccionaron los COC con base en la morfología citoplasmática y el número de capas de células de la granulosa (Ward et al., 2000). Los COC seleccionados se lavaron dos veces en medio de maduración in vitro (MIV) que contenía $8.3 \mathrm{~mL}$ de TCM199 (In Vitro, S.A. de C.V.), 10\% de SFB (Microlab), 5 UI/mL de hCG (Ferring Pharmaceuticals), $5 \mu \mathrm{g} / \mathrm{mL}$ de FSH (Merck Serono), 10 ng/mL de EGF y $0.65 \%$ (v:v) de Antibac-Antifun (In Vitro, S.A. de C.V.). En una caja de cuatro pozos (Nunc) previamente equilibrada con 500 $\mu \mathrm{L}$ de medio MIV y cubiertos con aceite mineral, se colocaron 50 COC en cada pozo y se dejaron incubar de 20 a 24 horas.

Clonación manual interespecies. Para la clonación ma- nual interespecies se siguió el método descrito por Vajta et al. (2001, 2006) y Peura \& Vajta (2003). Una vez completado el tiempo de maduración in vitro, los ovocitos con células del cúmulo expandidas se denudaron y fueron colocadas en un tubo cónico con $500 \mu \mathrm{L}$ de hialuronidasa $(0.5 \mathrm{mg} / \mathrm{mL}$ en TCM-199, In Vitro, S.A. de C.V.) resuspendiéndolas varias veces con una micropipeta automática.

Los ovocitos denudados se lavaron dos veces en T2 (TCM-199 suplementado con SFB al 2\%) para inactivar la acción enzimática y retirar el excedente de células de la granulosa. De los ovocitos denudados se seleccionaron aquellos que presentaron extrusión del primer cuerpo polar, los cuales se encontraban en Metafase II (MII). Éstos se colocaron en medio MIV con demecolcina a una concentración de $0.5 \mu \mathrm{g} / \mathrm{mL}$ y se incubaron 1 hora.

Preparación de los citoplastos. Se colocaron 4 gotas de $30 \mu \mathrm{L}$ correspondientes a las siguientes soluciones: T2, pronasa ( $2 \mathrm{mg} / \mathrm{mL}$ en T10), T10 (TCM-199 suplementado con $10 \%$ de SFB) y T20 (TCM-199 suplementado con 20\% de SFB), sobre una caja Petri de 60 x 15 mm. Las gotas se cubrieron con aceite mineral y en esta caja se prepararon los citoplastos.

Una vez finalizado el tiempo de incubación en demecolcina, los ovocitos se transfirieron a la gota de T2 de la caja de preparación de citoplastos. A continuación, se pasaron grupos de entre 20 a 30 ovocitos a la gota de pronasa por 3 minutos o hasta que la zona pelúcida se disgregara por completo. Inmediatamente después, los ovocitos libres de zona pelúcida se colocaron en la gota de T20 para inactivar la acción de la pronasa. Este procedimiento se repitió con todos los ovocitos disponibles.

Los ovocitos libres de zona pelúcida se distribuyeron en grupos de seis en cada una de las gotas de T10 y se prosiguió con su enucleación manual con ayuda de una micronavaja (Bioniche) y bajo un microscopio estereoscópico (Olympus ${ }^{\circledR}$, SZ61). Para ello, con la micronavaja se cortó la porción del citoplasma del ovocito cercana a la membrana, que contenía el material genético (placa metafásica y primer cuerpo polar). Los ovocitos enucleados (citoplastos) se colectaron en las gotas de T20 para que recuperaran su forma esférica y se determinaran como viables.

Formación y fusión de los tripletes citoplasto-carioplasto-citoplasto. Sobre la tapa de una caja Petri de 33 $\mathrm{mm}$ se colocaron gotas de $15 \mu \mathrm{L}$ de T20, fitohemaglutinina (5 mg/mL en TCM-199 con Hepes), T2 y medio de fusión (0.3 M de D-Manitol y $1 \mathrm{mg} / \mathrm{mL}$ de Polivinil Alcohol). Las gotas se cubrieron con aceite mineral. 
Los citoplastos se tomaron uno por uno y se fueron sumergiendo en la gota de fitohemaglutinina por 3 a 4 segundos, después se transfirieron a la gota de T2 que contenía una baja densidad de carioplastos (fibroblastos de hembra O. c. mexicana) y a continuación se formaron los tripletes citoplasto-carioplasto-citoplasto. Para ello, se unió un carioplasto con dos citoplastos colocando al primero entre los dos últimos.

Los tripletes formados se equilibraron en la gota de medio de fusión y se transfirieron a una cámara de fusión (BTX microslide, $0.5 \mathrm{~mm}$ de apertura, modelo 450). Se dejó pasar una corriente de $4 \mathrm{~V}$ de corriente alterna (en inglés AC) para alinear los tripletes al electrodo positivo, después se incrementó la AC a $9 \mathrm{~V}$ y se aplicó un soló pulso de $100 \mathrm{~V} / \mathrm{mm}$ de corriente directa (DC) por $9 \mu$ seg. Los tripletes se colocaron en las gotas de T20 y el procedimiento se repitió con los demás tripletes. Una vez que los tripletes formaron una sola célula, se incubaron 3 horas para la reprogramación nuclear en medio de desarrollo embrionario para cada tratamiento evaluado.

Activación. Los embriones reconstruidos (tripletes fusionados) se activaron por incubación en T2 que contenía $8 \mu \mathrm{M}$ de Ionóforo de $\mathrm{Ca}^{2+}$ (A23187) durante 5 minutos. Posteriormente se lavaron tres veces en T20 y se colocaron de manera individual en gotas de $2 \mu \mathrm{L}$ de medio de desarrollo embrionario suplementados con $2 \mathrm{mM}$ de 6-dimetilaminopurina (6-DMAP). Las gotas de medios se cubrieron con aceite mineral y se dejaron incubar por 4 horas a las mismas condiciones, al finalizar el tiempo de incubación en 6-DMAP, los embriones clones de hembra O. c. mexicana se lavaron tres veces en su correspondiente medio de desarrollo embrionario por espacio de $3 \mathrm{mi}-$ nutos en cada lavado.

Cultivo in vitro de embriones. Como se ha explicado, se utilizaron dos grupos de embriones reconstruidos de hembra Ovis canadensis mexicana para evaluar su desarrollo in vitro. El primero con 197 embriones cultivados 7 días en medio simple SOF (In Vitro, S.A. de C.V.) suplementado con 5\% de SFB, como grupo control (Vajta et al., 2003). Un segundo grupo de 60 embriones reconstruidos fueron cultivados en medio secuencial humano Cleavage-Blastocyst (Sydney IVF Cleavage Medium G20720 - Sydney IVF Blastocyst Medium G20722, Cook Medical) como grupo experimental.

El desarrollo in vitro de los embriones clones de hembra Ovis canadensis mexicana en medio secuencial humano consistió en cultivar los embriones durante 3 días en medio Cleavage, para favorecer la segmentación hasta la etapa de mórula compacta. Posteriormente los embriones clonados continuaron su desarrollo en medio Blastocyst hasta su desarrollo a la etapa de blastocisto. Para ello, al $4^{\circ}$ día de cultivo se transfirieron los embriones a un nuevo pozo con medio Blastocyst para un lavado y posteriormente se transfirieron al micropozo (WOW).

Los embriones clones de hembra Ovis canadensis mexicana de ambos grupos (simple y secuencial), se cultivaron en el sistema WOW, que consistió en hacer micropozos en cada celda de una caja de cuatro pozos de acuerdo al número de embriones clonados (Vajta et al., 2000). A cada celda se le agregaron $200 \mu \mathrm{L}$ del medio de desarrollo embrionario correspondiente (simple o secuencial) y se cubrieron con aceite mineral; se dejó equilibrar el medio por 4 horas y después se transfirieron cuidadosamente los embriones clonados a cada uno de los micropozos, se dejaron en incubación por 7 días.

Evaluación del desarrollo embrionario in vitro. A los 7 días de cultivo se evaluó el desarrollo embrionario in vitro de los dos grupos (control y experimental) bajo el microscopio estereoscópico a aumento de 20X. Se consideró la etapa de desarrollo en que se encontraban los embriones clones de hembra O. c. mexicana (desarrollados in vitro en medio simple y en medio secuencial). Se determinó el porcentaje de desarrollo in vitro para cada una de las etapas de la segmentación evaluadas (2 a 8 blastómeros, mórula, mórula compacta y blastocisto).

Evaluación de la calidad de los embriones clonados. La calidad embrionaria se determinó con base en la etapa de desarrollo esperada a los 7 días de cultivo (blastocisto). Posteriormente, los embriones se fijaron con paraformaldehído al 4\% durante 1 hora, se lavaron en $1 \mathrm{~mL}$ de DPBS (In Vitro, S.A. de C.V.) y se incubaron con Hoechst (5 $\mathrm{mg} / \mathrm{mL}$ de Hoechst, disuelto en DPBS con $1 \mathrm{~g} / \mathrm{L}$ de polivínil alcohol) durante 5 minutos. Finalizado este tiempo se realizó un lavado en DPBS y posteriormente se montaron los embriones sobre un portaobjetos con medio de montaje (1:1 v/v, glicerol-DPBS) y se cubrieron con un cubreobjetos cuyas orillas se sellaron con esmalte de uñas (Rodríguez-Suástegui, 2012). Los embriones montados se observaron bajo el microscopio de epifluorescencia (Nikon ${ }^{\circledR}$, eclipse E600) para evaluar el número de blastómeros y núcleos presentes.

Análisis Estadístico. Los datos obtenidos de las diferentes etapas de desarrollo de los embriones clonados de cada tratamiento se expresaron como número total, desviación estándar y porcentaje. Estos datos se analizaron con una prueba de Chi-cuadrada con el paquete estadístico SPSS versión 24.0. Las diferencias estadísticas fueron consideradas significativas bajo una $\mathrm{P}<0.05$. 


\section{RESULTADOS}

En el cuadro 1 y la figura 1 se muestran los resultados del desarrollo de embriones clones de hembra Ovis canadensis mexicana cultivados en medio simple SOF como grupo control y en medio secuencial humano CleavageBlastocyst como grupo experimental, a las 168 horas (7 días) de cultivo in vitro.

Se observa que en el medio simple se obtuvo una mayor tasa de división embrionaria comparado con el medio secuencial humano (95.4\% vs 93.3\%, $\mathrm{P}<0.05$ ).

Por otro lado, en el medio simple hubo embriones en las etapas de 2 a 4 blastómeros ( $4.8 \%$ vs $0.0 \%, \mathrm{P}<0.05$ ), y un mayor porcentaje de embriones de 8 blastómeros a mórula, comparado con el medio secuencial (95.2\% vs $75 \%, \mathrm{P}<0.05)$. Sin embargo, fue solo en el medio secuencial humano en el que se obtuvieron embriones clones de hembra O. c. mexicana en estadios de mórula compacta (8.9\% vs $0.0 \%, \mathrm{P}<0.05)$ y blastocisto $(16.1 \%$ vs $0.0 \%$, $\mathrm{P}<0.05)$.

Posterior a la tinción con Hoechst de los embriones clones de hembra Ovis canadensis mexicana obtenidos en cada tratamiento y tomando como base el número de núcleos presentes en cada blastómero, se determinó la tasa de fragmentación embrionaria, ya que ésta comúnmente se presenta en la producción in vitro de embriones. Se consideró como embrión fragmentado aquel que presentara blastómeros sin núcleo.

En el cuadro 2 se muestra que, el uso de medio secuencial humano permite un mayor porcentaje de embriones clones de hembra O. c. mexicana no fragmentados, en comparación con el medio simple (32.1\% vs. 5.9\%, $\mathrm{P}<0.05$ ).

La figura 2 muestra fotografías en panel de embriones

Cuadro 1. Desarrollo in vitro de embriones clones de hembra Ovis canadensis mexicana en medio simple y en medio secuencial humano a las 168 horas (7 días) de cultivo.

\begin{tabular}{lcccccc}
\hline Medio & No. de embriones & $\begin{array}{c}\text { Embriones } \\
\text { divididos } n \pm D E \\
(\%)\end{array}$ & $\begin{array}{c}2-4 \text { blastómeros } \\
\mathrm{n} \pm \mathrm{DE} \\
(\%)\end{array}$ & $\begin{array}{c}\text { 8 blastómeros a } \\
\text { mórula } \mathrm{n} \pm \mathrm{DE} \\
(\%)\end{array}$ & $\begin{array}{c}\text { Mórula compacta } \\
\mathrm{n} \pm \mathrm{DE} \\
(\%)\end{array}$ & $\begin{array}{c}\text { Blastocisto } \mathrm{n} \pm \mathrm{DE} \\
(\%)\end{array}$ \\
\hline Simple & 197 & $188 \pm 3.8(95.4)^{\mathrm{a}}$ & $9 \pm 0.9(4.8)^{\mathrm{a}}$ & $179 \pm 3.9(95.2)^{\mathrm{a}}$ & $0.0 \pm 0.0(0)^{\mathrm{a}}$ & $0.0 \pm 0.0(0)^{\mathrm{a}}$ \\
Secuencial & 60 & $56 \pm 3.7(93.3)^{\mathrm{b}}$ & $0.0 \pm 0.0(0)^{\mathrm{b}}$ & $42 \pm 4.4(75)^{\mathrm{b}}$ & $5 \pm 0.5(8.9)^{\mathrm{b}}$ & $9 \pm 1.7(16.1)^{\mathrm{b}}$ \\
\hline
\end{tabular}

Literales diferentes en la misma columna indican diferencias estadísticamente significativas, bajo el nivel de significancia de $\mathrm{P}<0.05$ para la prueba de $\mathrm{X}^{2}$.

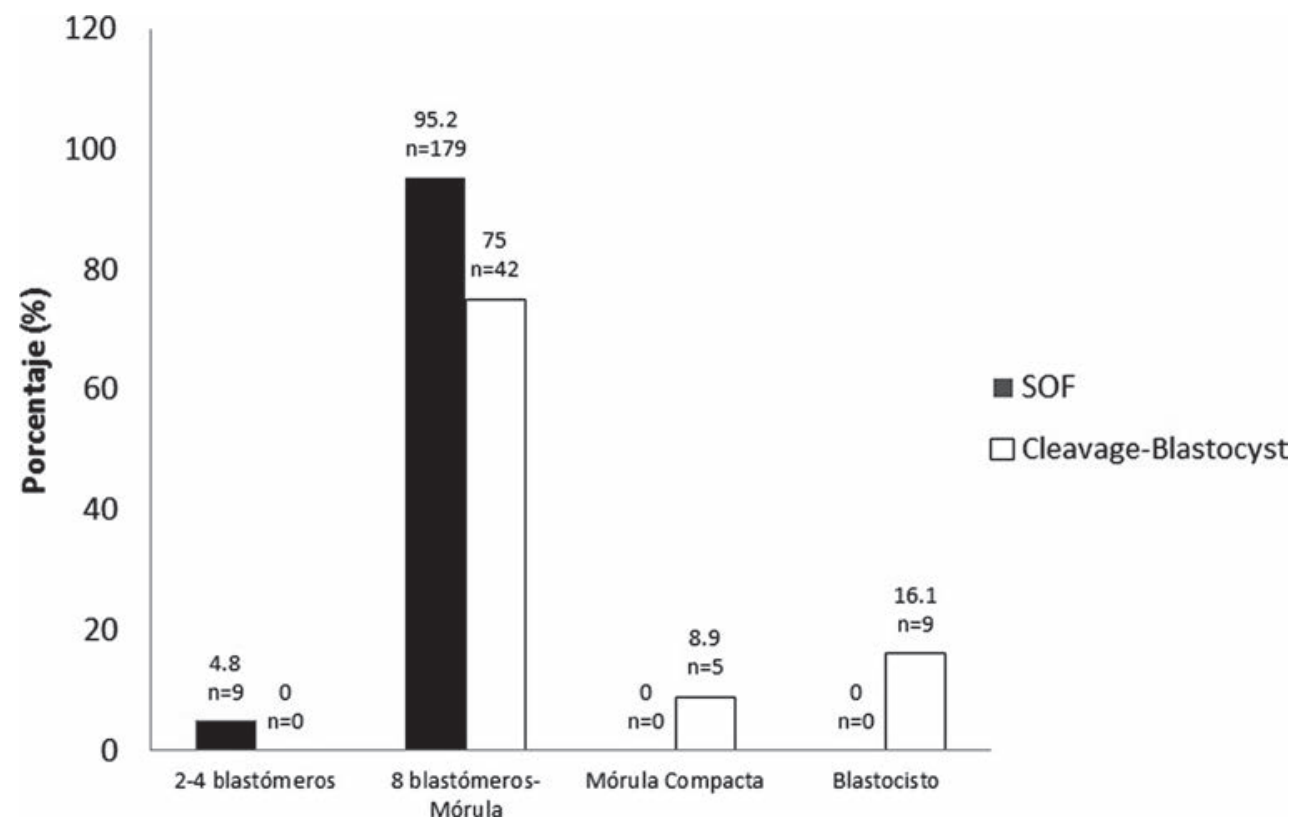

Figura 1. Desarrollo in vitro de embriones clones de hembra Ovis canadensis mexicana en medio simple y en medio secuencial humano a las 168 horas (7 días) de cultivo. 
Cuadro 2. Efecto del medio simple y medio secuencial humano sobre la tasa de fragmentación de embriones clones de hembra Ovis canadensis mexicana.

\begin{tabular}{lcc}
\hline Medio & No. de embriones & $\begin{array}{c}\text { No fragmentados } \\
\mathrm{n} \pm \mathrm{D} . \mathrm{E} . \\
(\%)\end{array}$ \\
\hline Simple & 188 & $11 \pm 1.1(5.9)^{\mathrm{a}}$ \\
Secuencial & 56 & $18 \pm 1.3(32.1)^{\mathrm{b}}$ \\
\hline
\end{tabular}

Literales diferentes en la misma columna indican diferencias estadísticamente significativas, bajo el nivel de significancia de $\mathrm{P}<0.05$ para la prueba de $\mathrm{X}^{2}$

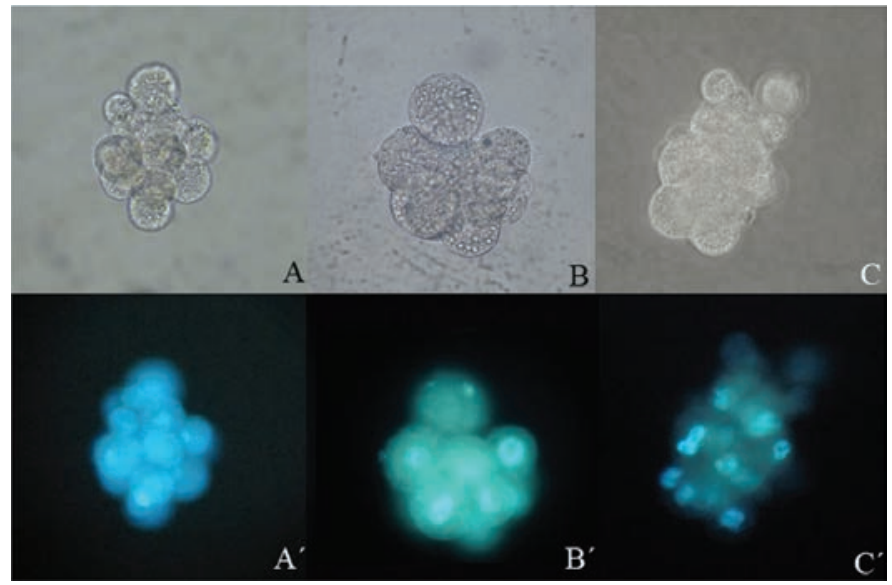

Figura 2. Embriones clones de hembra O. c. mexicana cultivados en medio simple SOF, antes y después de su tinción con Hoechst. A-A') 12 blastómeros. B-B') 9 blastómeros y C-C’) 17 blastómeros. Filtro de excitación de UV $350 \mathrm{~nm}$. Aumento 40X.

de 9 a 17 blastómeros clones de hembra O. c. mexicana, desarrollados en SOF antes y después de la tinción con Hoechst.

En la figura 3 se muestran fotografías en panel antes y después de la tinción con Hoechst, donde se observan embriones no fragmentados (2 mórulas y 1 blastocisto) clones de hembra O. c. mexicana, desarrollados en medio secuencial humano Cleavage-Blastocyst.

La figura 4 presenta dos embriones clones de hembra O. c. mexicana. La imagen A-A’ muestra un embrión fragmentado donde solo un blastómero presenta núcleo, mientras que la imagen B-B' corresponde a un embrión donde todos sus blastómeros presentan núcleos.

\section{DISCUSIÓN}

En el desarrollo embrionario aquí obtenido se observa que, a las 168 horas de cultivo in vitro, los embriones se

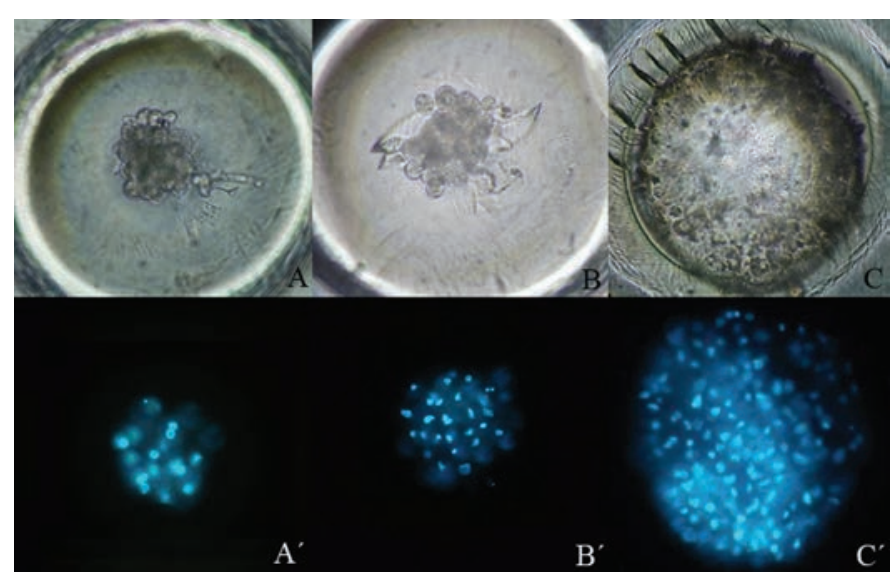

Figura 3. Embriones clones de hembra O. c. mexicana cultivados en medio secuencial humano Cleavage-Blastocyst, antes y después de su tinción con Hoechst. A-A’) Mórula. B-B') Mórula compacta. C-C’)

Blastocisto. Filtro de excitación de UV 350 nm. Aumento 40X.

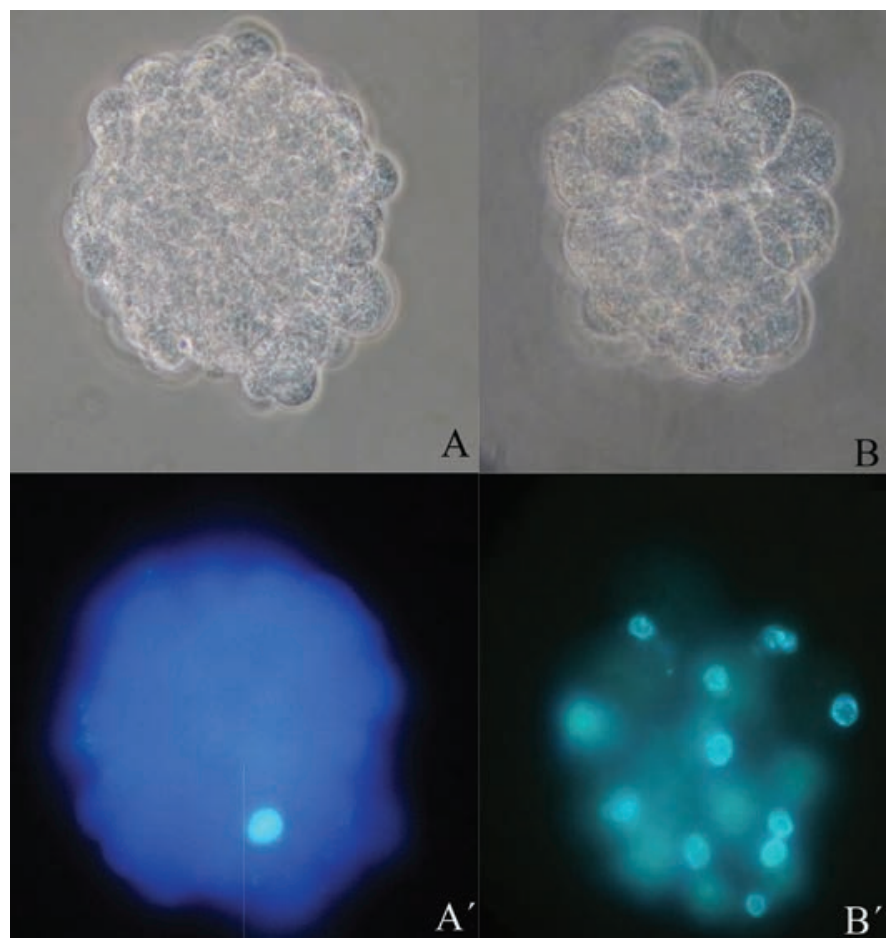

Figura 4. Embriones clones de hembra O. c. mexicana antes y después de su tinción con Hoechst. A-A') Embrión fragmentado

(solo un blastómero presenta núcleo). B-B’) Embrión dividido correctamente (cada blastómero con su respectivo núcleo). Filtro de excitación de UV 350 nm. Aumento 40X.

encontraban en diferentes etapas de la división embrionaria: 2 a 4 blastómeros (4.8\% en SOF), 8 blastómeros a mórula (95.2\% en SOF vs. $75 \%$ en Cleavage-Blasto- 
cyst), mórula compacta (8.9\% en Cleavage-Blastocyst) y blastocisto (16.1\% en Cleavage-Blastocyst). Esto apunta a que en el medio simple ocurrió una asincronía y retraso del desarrollo embrionario más marcado al compararlo con el medio secuencial humano.

Navarro et al., (2000) y Trejo et al., (2005), observaron una marcada asincronía y retraso del desarrollo in vivo de embriones en etapas de 2 blastómeros a mórula en hámster adulta, relacionado a un posible bloqueo del desarrollo embrionario correspondiente con el transporte del embrión del oviducto al útero y explican que esto puede deberse a la edad y paridad de la hembra, más que a factores de autoregulación del desarrollo y transporte del embrión. En el caso del presente trabajo, se utilizaron ovocitos de ovejas domésticas adultas como citoplastos y fibroblastos de oveja cimarrona también adulta como carioplastos, lo cual pudo influir en el bloqueo del desarrollo embrionario.

También ha sido reportado que el bloqueo del desarrollo embrionario se debe al Síndrome de Nacimientos de Crías Grandes o LOS (por sus siglas en inglés Large Offspring Syndrome), a causa de la manipulación bioquímica a que son sujetas las células que participan en la producción in vitro de embriones de mamíferos (McEvoy et al., 2001). Los autores señalan que ello influye en la presencia de pluriploidía (mixoploidías), aberración cromosómica que, si bien ocurre en embriones de animales domésticos morfológicamente normales, es consecuencia de la producción de embriones in vitro. Esta condición de pluriploidía (mixoploidías o mosaiquismos, triploidías y tetraploidías) también ha sido reportada en humanos (Pimentel et al., 1999).

Asimismo, se conoce que los sistemas de cultivo relacionados con la suplementación de sueros, generan estrés metabólico que afecta la expresión de genes del desarrollo embrionario y da lugar a la apoptosis celular (McEvoy et al., 2001). Es decir que, los mecanismos epigenéticos influyen en el control de la expresión de genes asociados con la pluripotencia del embrión, tales como Oct4, Sox2, Nanong y $C d x 2$, así como en el empaquetamiento de la cromatina, lo que conlleva a la apoptosis y muerte celular (Buemo et al., 2016).

Es probable que el medio de cultivo secuencial humano aquí evaluado, a diferencia del medio simple, reduzca el estrés metabólico embrionario por su aporte de nutrientes necesarios para cubrir las necesidades metabólicas y de energía correspondientes a cada etapa de la segmentación embrionaria (Dorado et al., 2006; Sanches et al., 2013). Ya que de acuerdo con la casa comercial
Cook Medical, el Sydney IVF Cleavage Medium es bajo en glucosa y alto en piruvato, para optimizar el desarrollo embrionario temprano (https://www.cookmedical.com/ products/wh_sicm_webds/). Mientras que el Sydney IVF Blastocyst Medium es alto en glucosa para maximizar el metabolismo, la producción de energía, la blastulación, la diferenciación y expansión del blastocisto. Además de incluir aminoácidos esenciales y no esenciales para el desarrollo del mismo (https://www.cookmedical.com/products/wh_sibm_webds/).

Respecto a la tasa de división de los embriones clones de hembra Ovis canadensis mexicana obtenidos en el presente trabajo (95.4\% en medio simple y $93.3 \%$ en medio secuencial humano), están por encima de lo encontrado por Priya et al., (2014) quienes obtuvieron 92\% de embriones divididos, y por Yu et al., (2011) que reportaron $70.14 \%$ de embriones divididos. Los autores no describen el medio de cultivo utilizado.

De la obtención de mórulas compactas en medio secuencial humano, los resultados aquí obtenidos (8.9\%) están por debajo de lo encontrado por Yu et al., (2011), que reportaron $100 \%$ de mórulas clones de antílope tibetano (Pantholops hodgsonii), sin embargo los autores no lograron obtener blastocistos.

Referente al porcentaje de blastocistos aquí obtenido (16.1\%), vemos que es menor al $38.7 \%$ obtenido por Priya et al., (2014) al aplicar la clonación manual interespecies de búfalo salvaje (Bubalus arnee) a partir de ovocitos de búfalo doméstico (Bubalus bubalis), utilizando medio RVCL.

Con respecto a otros ovinos silvestres originados por clonación tradicional (TNCS) interespecies en medio simple SOFm, los resultados obtenidos en el presente trabajo están por encima de lo encontrado por Pan et al., (2014) quienes lograron $88.1 \%$ de embriones divididos clones de borrego argali (Ovis ammon), pero por debajo de ellos en cuanto a la obtención de blastocistos, que en dicho trabajo fue del $21.5 \%$.

Sin embargo, nuestros resultados están por encima de lo encontrado por Stroud et al., (2013) que obtuvieron $65 \%$ de embriones divididos y $2 \%$ de blastocistos clones de borrego cimarrón del desierto de EUA (Ovis canadensis canadensis), utilizando SOFm.

En el presente estudio, la clonación manual (HMC) interespecies, mostró ser eficaz en la obtención de blastocistos de hembra Ovis canadensis mexicana, como sucediera para Yu et al., (2011) y para Priya et al., (2014), que aplicaron la clonación manual interespecies para obtener 
embriones de antílope tibetano y búfalo salvaje, respectivamente.

De los embriones clones de hembra Ovis canadensis mexicana fragmentados aquí obtenidos, se observó presencia de blastómeros sin núcleo presente en algunos embriones y en otros, la presencia de más de un núcleo por blastómero.

La fragmentación embrionaria, común en la clonación, se da a dos niveles. Uno es a nivel del ADN, a causa de la manipulación ejercida sobre los ovocitos utilizados como citoplastos y las células somáticas utilizadas como carioplastos, e influye en la división embrionaria, ya que un número importante de embriones clonados no alcanza la etapa de blastocisto en porcentajes que posibiliten la eficiencia en la transferencia embrionaria, el desarrollo fetal y el nacimiento de crías viables (Buemo et al., 2016).

Otra es la fragmentación citoplasmática, que se ha descrito como la presencia de porciones citoplasmáticas rodeadas de membrana que carecen de núcleos y se presentan durante el desarrollo embrionario (Kawahara et al., 2002; Fujimoto et al., 2011). Esta condición se presenta después de la activación del ovocito para iniciar la segmentación y acontece específicamente durante la fase de citocinesis del ciclo celular en los blastómeros en división, en respuesta a una inadecuada sincronización entre los microtúbulos del huso y los microfilamentos corticales (Alikani et al., 2005).

El medio secuencial humano aquí utilizado (Cleavage-Blastocyst), no solo redujo el bloqueo del desarrollo embrionario, sino que favoreció considerablemente el desarrollo de embriones viables (no fragmentados), comparativamente con el SOF (32\% vs. 6\%, respectivamente). Es necesario evaluar si esto pudo deberse a la eliminación de los productos tóxicos generados por el propio metabolismo embrionario, gracias al sistema de cultivo secuencial que implica retirar los embriones del medio en que se encuentran los 3 primeros días de cultivo, para colocarlos en un medio nuevo donde continúen su desarrollo por 4 o 5 días más (Findikli et al., 2004).

Findikli et al., (2004) utilizando medios secuenciales G1.2/G2.2 e ISM1/ISM2, produjeron 23\% de blastocistos humanos por ICSI (por sus siglas en inglés Intracitoplasmic Sperm Injection) en el primer medio secuencial evaluado. Sin embargo, observaron un mayor número de embriones en la etapa de 8 células en el segundo medio secuencial, explicando que pudiera deberse a un factor mitótico presente en dicho medio. Esto pudo suceder también en el caso del presente reporte, en donde observamos una mayor tasa de embriones de 8 blastómeros en el medio simple (SOF) en comparación con el medio secuencial humano (Cleavage-Blastocyst) (95.2\% vs. 75\%, respectivamente).

Otros factores que influyen en el éxito de los cultivos in vitro es la reducción de la presencia de especies reactivas de oxígeno (ERO) tales como peróxido de oxígeno $\left(\mathrm{H}_{2} \mathrm{O}_{2}\right)$, radical hidroxilo y radical peróxido, producto de la cadena respiratoria mitocondrial del embrión (RochaFrigoni et al., 2016). Ya que la producción de ERO en los sistemas de cultivo in vitro de embriones se debe a que son sometidos a presiones del $\mathrm{O}_{2}$ (presente en la incubadora) mayores a las existentes en el tracto reproductor de la hembra ( $20 \%$ vs. $3-9 \% \mathrm{O}_{2}$ en el tracto reproductor en bovinos). Lo anterior reitera que los aspectos epigenéticos de la interacción con el medio de cultivo, son de trascendencia, por lo que se requiere estudiarlos en detalle.

Por otro lado, se sabe que la fragmentación embrionaria está asociada a una baja viabilidad del embrión, que ocurre en la primera división celular en un $40 \%$ de los embriones producidos in vitro y puede estar ligada a la presencia de ERO (Halvaei et al., 2016).

En el presente trabajo, los embriones clonados y desarrollados en SOF mostraron fragmentación citoplasmática y algunos blastómeros polinucleares. La fragmentación en embriones obtenidos por clonación se ha relacionado con los estímulos eléctricos aplicados a los carioplastos y citoplastos durante la fusión celular y activación, los cuales desestabilizan los microfilamentos de actina promoviendo la fragmentación citoplasmática (Kawahara et al., 2002; IM et al., 2005).

Si bien la producción de blastocistos de hembra Ovis canadensis mexicana aquí obtenida fue relativamente baja (16.1\%), se demuestra la capacidad del ovocito de ovino doméstico (Ovis aries) para reprogramar fibroblastos de piel utilizados como carioplastos, de un ovino silvestre de México.

\section{CONCLUSIONES}

De acuerdo con los resultados obtenidos, el presente es el primer reporte exitoso de producción de embriones que alcanzan la etapa de blastocisto por clonación manual interespecies, utilizando fibroblastos de piel de oreja de borrega silvestre (Ovis canadensis mexicana) como donadores de núcleo, fusionándolos con ovocitos enucleados de borrega doméstica (Ovis aries).

El interés por implementar biotecnologías reproductivas de vanguardia en especies silvestres, radica en aportar 
una alternativa más en la conservación de fauna silvestre endémica de nuestro País en algún nivel de riesgo. Sin embargo, es necesario continuar mejorando los cultivos in vitro de los embriones clonados para reducir al máximo los factores que puedan estar influyendo en el fenómeno de la fragmentación embrionaria, garantizando así la viabilidad y condición óptima de los embriones.

\section{LITERATURA CITADA}

Aghaz, F., Hajarian, H. \& KaramiShabankareh H. (2016). In vitro culture medium (IVC) supplementation with sericin improves developmental competence of ovine zygotes. Reproductive Biology, 16, 87-90.

Akshey, Y. S., Malakar, D. \& De, A. K. (2008). Production of handmade cloned goat blastocysts using fetal fibroblast cells. Reproduction Fertility and Development, 20, 91-92.

Alikani, M., Schimmel, T. \& Willadsen, S. M. (2005). Cytoplasmic fragmentation in activated eggs occurs in the cytokinetic phase of the cell cycle, in lieu of normal cytokinesis, and in response to cytoskeletal disorder. Molecular Human Reproduction, 11, 335-344.

Arias, M. E., Ross, P. J. \& Felmer, R. N. (2013). Culture medium composition affects the gene expression pattern and in vitro development potential of bovine somatic cell nuclear transfer (SCNT) embryos. Biology Research, 46, 452-462.

Bosch, P. (2005). Clonado de animales mediante transferencia nuclear, aplicaciones en ganadería y biomedicina. Pp.620-625. In: González-Stagnaro \& Soto-Belloso E. Manual de Ganadería Doble Propósito. Astro Data, S. A. Maracaibo-Venezuela.

Buemo, C. P., Gambini, A., Moro, L. M., Hiriart, M. I., Fernández-Martín, R., Collas, P. \& Salamone, D. F. (2016). Embryo aggregation in pig improves cloning efficiency and embryo quality. Plos One. doi:10.1371/journal.pone.0146390.

Cevik, M., Kocyigit, A., Sen, U. \& Kuran, M. (2014). Can sequential human embryo culture media be used in bovine in vitro embryo culture? Journal of the Faculty of Veterinary Medicine, Kafka University, 20, 145-149.

Dorado, M., Marqués de Oliveira, N., Lorenzo, C., Vázquez, G. \& Marco, Y. (2006). Evolución de los medios de cultivo embrionario en técnicas de reproducción asistida. Revista Iberoamericana de Fertilidad, 23, 31-36.

Du, Y., Lin, L., Schmidt, M., Bøgh, I. B., Kragh, P. M., Sørensen, C. B., Li, J., Purup, S., Pribenszky, C., Molnár, M., Kuwayama, M., Zhang, X., Yang, H., Bolund, L., \& Vajta, G. (2008). High hydrostatic pressure treatment of porcine oocytes before handmade cloning improves developmental competence and cryosurvival. Cloning and Stem Cells, 10, 325-330.

Escalante, T., Espinosa, D. \& Morrone, J. J. (2002). Patrones de distribución geográfica de los mamíferos terrestres de México. Acta Zoológica Mexicana, 87, 47-65.

Findikli, N., Kahraman, S., Donmez, E., Sertyel, S., Melil, S. \& Benkhalifa, M. (2004). Comparison of embryo development in sibling oocytes cultured in two different sequential media. Middle East Fertility Society Journal, 9, 150-175.
Fujimoto, V. Y., Browne, R. W., Bloom, M. S., Sakkas, D. \& Alikani, M. (2011). Pathogenesis, developmental consequences, and clinical correlations of human embryo fragmentation. Fertility and Sterility, 95, 1197-1204.

García-García, R. M., Ward, F., Fair, S., O’Meara, C. M., Wade, M., Duffy P. \& Lonergan, P. (2007). Development and quality of sheep embryos cultured in commercial G1.3/G2.3 sequential media. Animal Reproduction Science, 98, 233-240.

Halvaei, I., Ali, K. M., Esfandiari, N., Safari, S., Reza, T. A., Miglietta, S. \& Nottola S. A. (2016). Ultrastructure of cytoplasmic fragments in human cleavage stage embryos. Journal of Assisted Reproduction and Genetics. doi:10.1007/s10815-016-0806-1.

Hosseini, S. M., Hajian, M., Ostadhosseini, S., Forouzanfar, M., Abedi, P., Jafarpour, F., Gourabi, H., Shahverdi, A. H., Vosough, A., Ghanaie, H. R. \& Nasr-Esfahani M. H. (2015). Contrasting effects of G1.2/G2.2 and SOF1/SOF2 embryo culture media on pre- and post-implantation development of non-transgenic and transgenic cloned goat embryos. Reproductive Biomedicine OnLine. 31, 372-383.

IM, G. S., Yang, B. S., Lai, L., Hao, Y. \& Prather, R. S. (2005). Fragmentation and development of preimplantation porcine embryos derived by parthenogenetic activation and nuclear transfer, Molecular Reproduction and Development, 71, 159-165.

Kawahara, M., Mori, T., Tanaka, H. \& Shimizu, H. (2002). The suppression of fragmentation by stabilization of actin filament in porcine enucleated oocytes. Theriogenology, 58, 1081-1095.

Khan, F. A., Bhat, M. H., Yagoob, S. H., Waheed, S. M., Naykoo, N. A., Athar, H., Khan, H. M., Fazili, M. R., Ganai, N. A., Singla, S. K. \& Shah R. A. (2014). In vitro development of goatsheep and goat-goat zona-free cloned embryos in different culture media. Theriogenology, 81, 419-423.

McEvoy, T. G., Robinson, J. J. \& Sinclair, K. D. (2001). Developmental consequences of embryo and cell manipulation in mice and farm animals. Reproduction, 122, 507-518.

Navarro, M. C., Ambríz, D. G., Mundo, E.R., Trejo, A. C., Hernández O. P., Rosado A. G. (2000). Desarrollo embrionario temprano en el hámster sirio dorado, Mesocricetus auratus (Mammalia: rodentia). Acta Zoológica Mexicana (n.s.), 81, 105-115.

Navarro-Maldonado, M. C., Hernández-Martínez, S., VázquezAvendaño, J. R., Martínez-Ibarra, J. L., Zavala-Vega, N. L., Vargas-Miranda, B., Rivera-Rebolledo, J. A. \& Ambríz-García D. A. (2015). Epitelial cells derived from Ovis canadensis mexicana thawed skin tissue for a germplasm bank. Acta Zoológica Mexicana, 31, 275-282.

Navarro, M. M. C., Hernández, M. S., Martínez, I. J., Vázquez, A. R., Ambríz, G. D. A., Rangel, S. R. \& Vajta, G. (2016). Clonación de embriones de Ovis aries utilizando fibroblastos criopreservados durante14 meses. Revista Iberoamericana de Ciencias, 3, 45-53.

Pan, X., Zhang, Y., Guo, Z. \& Wang, F. (2014). Development of interspecies nuclear transfer embryos reconstructed with argali (Ovis ammon) somatic cells and sheep ooplasm. Cell Biology International, 38, 211-218.

Peura, T. \& Vajta, G. (2003). A comparison of established and new approaches in ovine and bovine nuclear transfer. Cloning and Stem Cells, 5, 257-277.

Pimentel, B. H. Lantigua, C. A. \& Quiñones, M. O. (1999). Mixo- 
ploidía diploide - tetraploide: primer reporte en nuestro medio. Revista Cubana de Pediatría, 71, 168-173.

Priya, D., Selokar, N. L., Raja, A. K., Saini, M., Sahare, A. A., Nala, N., Palta, P., Chauhan, M. S., Manik, R. S. \& Singla, S. K. (2014). Production of wild buffalo (Bubalus arnee) embryos by interspecies somatic cell nuclear transfer using domestic buffalo (Bubalus bubalis) oocytes. Reproduction in Domestic Animals, 49, 343-351.

Rocha-Frigoni, N. A., Leão, B. C., Dall'Acqua, P. C. \& Mingoti, G. Z. (2016). Improving the cytoplasmic maturation of bovine oocytes matured in vitro with intracellular and/or extracellular antioxidants is not associated with increased rates of embryo development. Theriogenology, XXX: 1-9. (in press).

Robledo-Verduzco, J. M., Herrera-Camacho, J., Cajero-Juárez, M., Navarro-Maldonado, M. C. \& García-Valladares, A. (2009). Evaluación de dos medios de maduración in vitro para la producción de embriones ovinos. Tropical and Subtropical Agroecosystems, 10, 95-9.

Rodríguez-Suástegui, J. L. (2012). Evaluación de desarrollo embrionario in vitro en ovino utilizando medio de cultivo permanente y secuencial. Universidad Autónoma Metropolitana, Iztapalapa. Tesis de Maestría en Biología Experimental.

Sanches, B. V., Pontes, J. H. F., Basso, A. C., Ferreira, C. R., Perecin, F. \& Seneda, M. M. (2013). Comparison of Synthetic Oviductal Fluid and G1/G2 Medium under low-1 oxygen atmosphere on embryo production and pregnancy rates in Nelore (Bos indicus) cattle. Reproduction in Domestic Animals, 48: e7-e9.

Sfontouris, I. A., Kolibianakis, E. M., Lainas, G. T., Petsas, G. K., Tarlatzis, B. C. \& Lainas, T. G. (2017). Blastocyst Development in a Single Medium Compared to Sequential Media: A Prospective Study With Sibling Oocytes. Reproductive Sciencies: 1-7. doi: 10.1177/1933719116687653.

Shaw, G. (1804). The Canadian sheep. Plate 610, the description and the index. In: Naturalist's Miscellany: G. Shaw and E. Nodder. Nodder and Co., London. Vol. 15 (unpaginated).

Soberano-Martínez, A., Bravo-Patiño, A., Olivo-Zepeda, I., Toscano-Torres, I., Cajero-Juárez, M., Herrera-Camacho, J., Navarro-Maldonado, M. C. \& Segura-Correa J. C. (2011). Fertilización de ovocitos caprinos madurados en dos medios de cultivo. Tropical and Subtropical Agroecosystems, 14, 301-307.

Solter, D. (2000). Mammalian cloning: advances and limitations. $\mathrm{Na}-$ ture Reviews Genetics, 1, 199-207.
Stroud, T., Xiang, T., Romo, S. \& Kjelland, E. (2013). 30 Rocky mountain bighorn sheep (Ovis canadensis canadensis) embryos produced using somatic cell nuclear transfer. Reproduction and Fertility Development, 26, 113-113.

Sydney IVF Blastocyst Medium. Cook Medical. https://www.cookmedical.com/products/wh_sibm_webds/

Sydney IVF Clevagae Medium. Cook Medical. https://www.cookmedical.com/products/wh_sicm_webds/

Tian, C. X., Kubota, C., Enright, B. \& Yang, X. (2003). Cloning animals by somatic cell nuclear transfer - biological factors. Reproductive Biology and Endocrinology, 1, 1-7.

Trejo, C. A., Navarro, M. C., Ambriz, G. D. \& Rosado, A. (2005). Effect of maternal age and parity on preimplantation embryo development and transport in the golden hamster (Mesocricetus auratus). Laboratory Animals, 39, 290-297.

Vajta, G., Peura, T., Holm, P., Páldi, A., Greve, T., Trounson, A. O. \& Callenseen, H. (2000). New method for culture of zona-included zona free embryos: The Well of the Well (WOW) system. Molecular Reproduction and Development, 55, 256-264.

Vajta, G., Lewis, I. M., Hyttel, P., Thouas, G. A. \& Trounson A. O. (2001). Somatic cell cloning without micromanipulators. Cloning, 3, 89-95.

Vajta, G., Lewis, I. M., Trounson, A. O., Purup, S., Maddox-Hyttel, P., Schmidt, M., Pedersen, H. G., Greve, T. \& Callesen, H. (2003). Handmade Somatic Cell Cloning in Cattle: Analysis of Factors Contributing to High Efficiency in vitro. Biology of Reproduction, 68, 571-578.

Vajta, G., Lewis, I. M. \& Tecirlioglu, R. T. (2006). Handmade somatic cell cloning in cattle. Methods in Molecular Biology, 348, 183-196.

Ward F. A., Lonergan P., Enright M. P. \& Boland M. P. (2000). Factors affecting recovery and quality of oocytes for bovine embryo production in vitro using ovum pick-up technology. Theriogenology, 54, 433-446.

Yu, H. H., Guo, Z. L., Qi, D. L., Yang, X. L., Yue, P. P., Cao, H., Xie, L. \& Zhao, X. Q. (2011). Interspecies embryo reconstruction in Tibetan antelope (Pantholops hodgsonii) by handmade cloning. African Journal Online, 10, 2360-2365.

Zhang, P., Liu, P., Dou, H., Chen, L., Chen, L., Lin, L., Tan, P., Vajta, G., Gao, J., Du, Y. \& Runlin, Z. M. (2013). Handmade cloned transgenic sheep rich in Omega-3 fatty acids. Plos One, 8, 1-9. 